\title{
Preparation and Characterization of Carbon Nanotubes/Hydroxyethyl Cellulose Hybrid Material
}

\author{
Gang Ke
}

\begin{abstract}
Hybrid material of multiwalled carbon nanotubes (MWNTs) and hydroxyethyl cellulose (HEC) was prepared by an efficient method that comprises shorten, chain extension, active groups introducing and homogeneous reaction process. The hybrid material (MWNT-HEC) was characterized by FTIR, XPS spectroscopies, thermogravimetric analysis and transmission electron microscopy. Results confirm the covalent conjugate of the nanotubes and the cellulose chains. The hybrid material consists of carbon $(\mathbf{7 6 . 2 \%})$, oxygen $(19.5 \%)$ and nitrogen $(4.3 \%)$. With a nanotube-attached hydroxyethyl cellulose content of $32.1 \mathrm{wt} \%$, the MWNT-HEC is readily soluble in common polar solvents, which makes it possible to mix the hybrid material together with certain cellulose matrices in homogeneous systems in next application step. Further studies aiming at potential applications in specific sorption \& isolation and delivery systems are in process.
\end{abstract}

Index Terms-Carbon nanotubes, hydroxyethyl cellulose, hybrid material, preparation.

\section{INTRODUCTION}

It has been proved to be an effective way to create various hybrid materials with unprecedented properties by covalent functionalization of carbon nanotubes with polymers [1], [2]. To achieve this, it is essential to functionalize the nanotubes with ideal polymers.

As a distinctive non-ionic and water-soluble material from nature, hydroxyethyl cellulose (HEC) is one of the most important cellulose ether, and has broad applications in drug delivery systems, cosmetics, adhesives, coatings, dyeings, paper making additives, textiles, etc. [3], [4]. Similarly, the carbon nanotubes have shown attractive capabilities in selective adsorption and isolation, as well as drug and other delivery systems, owing to unique structures of the nanotubes [5]-[7]. Thus, the opportunity to functionalize the carbon nanotubes with the hydroxyethyl cellulose appears as a desirable way to develop environment-friendly hybrid materials with special properties originated in both components.

\section{EXPERIMENTAL}

\section{A. Materials}

Hydroxyethyl cellulose with the degree of substitution of 1.3 and the viscometric average molecular weight $\left(\mathrm{M}_{\mathrm{v}}\right)$ of

Manuscript received November 7, 2016; revised February 20, 2017.

G. Ke is with the State Key Laboratory of Seismic Reduction/Control and Structural Safety, Guangzhou University, Guangzhou 510006, China (e-mail: hustkg@163.com).
$1.1 \times 10^{5}$ was obtained from SCRC, China. MWNTs were purchased from Shenzhen Nanotech Port Co. (China). Other reagents used were of analytical grade.

\section{B. Preparation for Triazine-Functionalized MWNTs (MWNT-triazine)}

After ball-milling, purification and oxidation, MWNTs $(7.56 \mathrm{~g})$ in $\mathrm{SOCl}_{2}(300 \mathrm{ml})$ together with $\mathrm{N}, \mathrm{N}$ 'dimethylformamide (DMF, $60 \mathrm{ml}$ ) were refluxed for $72 \mathrm{~h}$ to obtain nanotubes bearing acyl chlorides. After solvent removal, 1,3-propanediamine (1.90 g), triethylamine $(22 \mathrm{ml})$ and acetone $(330 \mathrm{ml})$ were added. The mixture was sonicated for $1.5 \mathrm{~h}$, then stirred and refluxed under nitrogen for $50 \mathrm{~h}$. After successive procedures of solvent removal, redissolve in acetone, sonication, filtration, water-wash and dryness, MWNTs bearing amino groups were obtained (weight of MWNT- $\mathrm{NH}_{2}: 7.28 \mathrm{~g}$ ).

After dissolution of 2,4,6-trichloro-1,3,5-triazine (2.25 g) in THF $(120 \mathrm{ml})$, an ice bath was utilized to maintain temperature of the system below $5^{\circ} \mathrm{C}$. To the mixture, a solution of the MWNT- $\mathrm{NH}_{2}(6.10 \mathrm{~g})$ in THF $(160 \mathrm{ml})$ was added slowly for $12 \mathrm{~h}$ with vigorous stirring. The reaction was further carried out over a period of $50 \mathrm{~h}$. Then the mixture was quickly filtered through a $0.22-\mu \mathrm{m}$ pore size PTFE membrane. The black residue was further extracted with anhydrous acetone in a Soxhlet apparatus at ambient temperature for 48 $\mathrm{h}$, in order to eliminate the excess triazine compound. The final product was dried under vacuum for $24 \mathrm{~h}$ (weight of MWNT-triazine: $5.41 \mathrm{~g}$ ).

\section{Preparation for Hybrid Material of the MWNTs and Hydroxyethyl Cellulose}

Hydroxyethyl cellulose $(2.25 \mathrm{~g})$ in pyridine $(60 \mathrm{ml})$ was stirred at ambient temperature for $2 \mathrm{~h}$. Then a solution of MWNT-triazine $(0.60 \mathrm{~g})$ in DMF $(60 \mathrm{ml})$ was added. The mixture was sonicated for $1 \mathrm{~h}$ and vigorously stirred for $1 \mathrm{~h}$. Then the mixture was heated to $40^{\circ} \mathrm{C}$ under nitrogen. The reaction was carried out at $40{ }^{\circ} \mathrm{C}$ over a period of $6 \mathrm{~h}$. Subsequently, the temperature was raised up to $90{ }^{\circ} \mathrm{C}$ and maintained for $48 \mathrm{~h}$. Followed by a complete removal of solvents, the black residue was sonicated in distilled water $(200 \mathrm{ml})$ for $30 \mathrm{~min}$, and then filtered through a $0.8-\mu \mathrm{m}$ pore size nylon filter. After the residue was rinsed with distilled water $(1 \mathrm{~L})$, the residue was sonicated in distilled water $(900$ $\mathrm{ml}$ ) for $30 \mathrm{~min}$ and stirred for $2 \mathrm{~h}$. Again the mixture was filtered through nylon membrane. After the rinse-sonicationstir-filtration procedure repeated for another ten times, the residue was further extracted with distilled water in a Soxhlet apparatus at ambient temperature for $72 \mathrm{~h}$, so as to eliminate the excess HEC. The final product was dried under vacuum 
for $48 \mathrm{~h}$ (weight of MWNT-HEC: $0.93 \mathrm{~g}$ ).

\section{Characterization}

XPS was conducted on a Kratos XSAM 800 spectrometer with a magnesium anode at $400 \mathrm{~W}, 15 \mathrm{kV}$, and $27 \mathrm{~mA}(\mathrm{Mg}$ $\mathrm{K} \alpha 1253.6 \mathrm{eV}$, type 10-360 spherical capacitor analyzer). TEM images were obtained from a FEI Tecnai G2 20 operating at $200 \mathrm{kV}$. FTIR spectra were recorded on a Bruker VERTEX 70 spectrometer from $\mathrm{KBr}$ pellets. TGA experiments were carried out on a PerkinElmer Pyris $I$ TGA system with a typical heating rate of $10{ }^{\circ} \mathrm{C} \cdot \mathrm{min}^{-1}$ in a $\mathrm{N}_{2}$ atmosphere.

\section{RESULTS AND DISCUSSION}

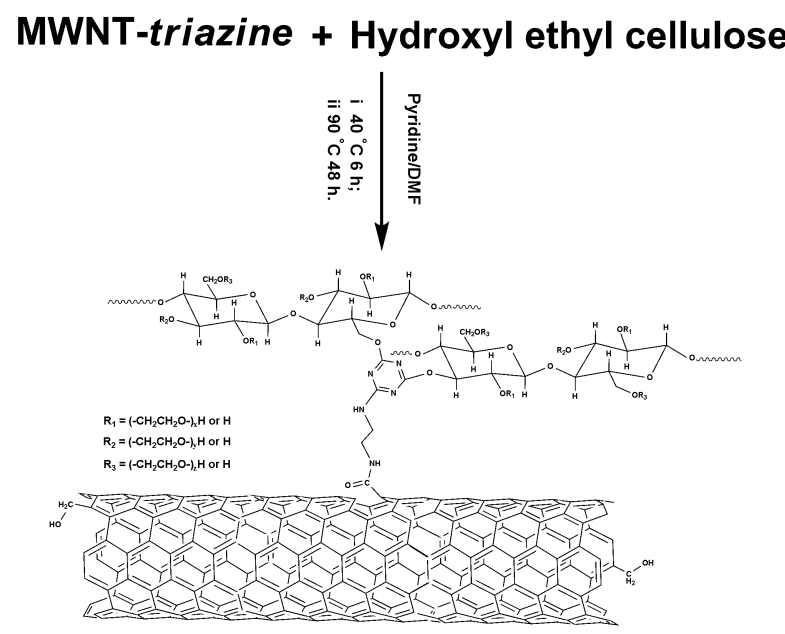

Fig. 1. Scheme of preparation of the hybrid material (MWNT-HEC)

Aiming at an efficient graft, it is vital to introduce sufficient and more active groups that can react with hydroxyls of the HEC to the nanotube sidewalls. Thus, a strategy that consists of cutting, chain extension, introducing active groups and homogeneous reaction tactics was employed to functionalize the MWNTs with the HEC. The MWNT-triazine dissolves in DMF, DMAc and DMSO, which helps make the preparation of the hybrid material via homogeneous reaction become reality, as shown in Fig. 1. Based on following considerations, a mixture of pyridine/DMF with a volume ratio of 1:1 was chosen as the medium. (i) The reaction comprises a lower temperature stage $\left(40{ }^{\circ} \mathrm{C}\right)$ and a higher temperature stage $\left(90{ }^{\circ} \mathrm{C}\right)$. With a boiling temperature of $153-154{ }^{\circ} \mathrm{C}$, DMF matches this need. (ii) As a common alkaline solvent in the nucleophilic substitution reactions, DMF avails to absorb chlorine hydride released in attacks of the HEC molecules on the MWNT-triazine. (iii) The HEC is soluble in pyridine, and pyridine also avails to absorb chlorine hydride.

After the successive procedures of separations, a black product was obtained. By TEM imaging, as shown in Fig. 2(c, d), it depicts representative features showing the shortened nanotubes compactly coated with a distinct amorphous polymeric material. On one hand, as the product was carefully separated by sonication, rinse and repeated extraction with acetone, any soluble HEC should be removed previously. Here, the amorphous material should not be un-reacted or unbounded HEC, otherwise it would spread all over the carbon diaphragm and not localize just on the nanotubes.
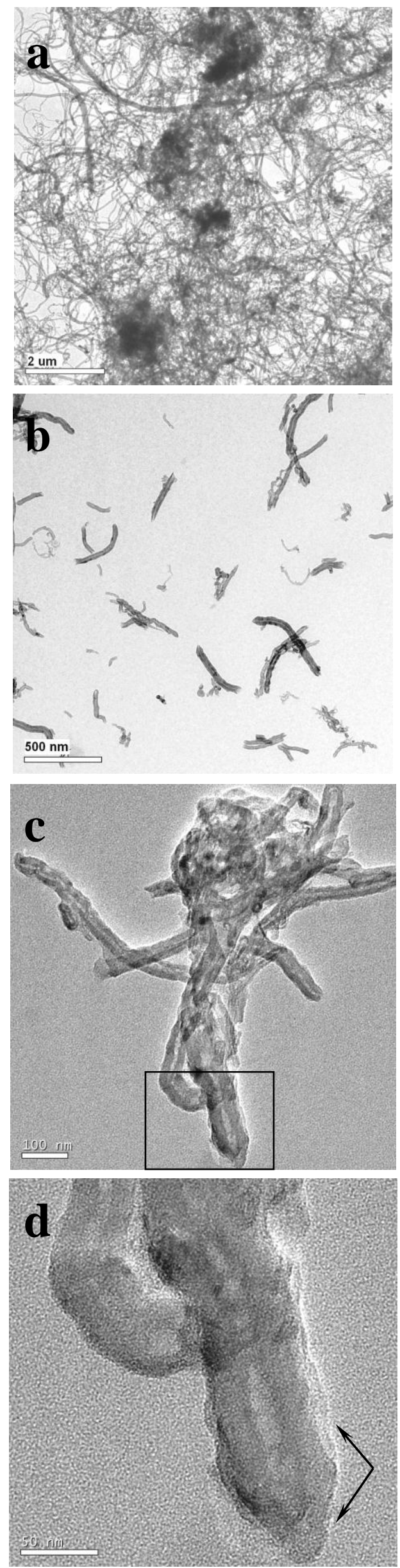

Fig. 2. TEM images of (a) raw MWNTs, (b) shortened, purified and acid oxidized MWNTs, and (c, d) MWNT-HEC (Arrows indicate the typical features of attached HEC). 
On the other hand, there is not any detectable clearance between the material and nanotube surfaces. Such a tight conglutination of two distinct materials should not be a result from physical adsorption. Take all these into account, the material surrounding the nanotubes was deduced to be covalently attached HEC moieties. Consequently, the purified single resultant, which was considered as the hydroxyethyl cellulose-functionalized MWNTs (MWNT-HEC), was worthy of detailed investigation and confirmation.

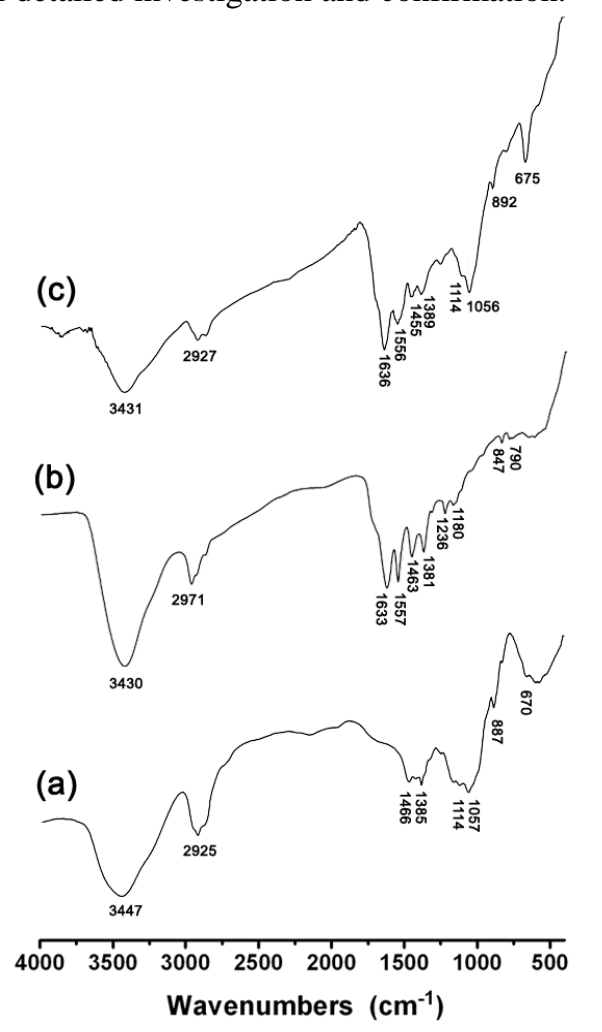

Fig. 3. FTIR spectra of (a) HEC, (b) MWNT-triazine and (c) MWNT-HEC.

FTIR spectra of the HEC, MWNT-HEC and MWNTtriazine are shown in Fig. 3. As shown in Fig. 3(b), characteristic absorptions relating to triazine ring occur at 1557,847 and $790 \mathrm{~cm}^{-1}$, respectively. The $1557 \mathrm{~cm}^{-1}$ band is attributable to stretching of $\mathrm{C}=\mathrm{N}$ in triazine rings [8]; the 847 $\mathrm{cm}^{-1}$ band arises from skeleton vibration of the triazine ring; and the $790 \mathrm{~cm}^{-1}$ absorption is due to $\mathrm{C}-\mathrm{Cl}$ vibration.

In FTIR spectrum of the MWNT-HEC (Fig. 3(c)), three characteristic bands of the HEC appear at 675, 892 and 1056 $\mathrm{cm}^{-1}$, respectively. Moreover, $\mathrm{C}-\mathrm{Cl}$ stretching of the MWNT-triazine at $791 \mathrm{~cm}^{-1}$ was absent after functionalization. Additionally, vibration absorption of triazine ring skeleton at $1557 \mathrm{~cm}^{-1}$ shifted to $1541 \mathrm{~cm}^{-1}$ and much weakened after modification. These changes suggest that chlorine atoms in the MWNT-triazine have been substituted. It conduced to a linkage formation between the triazine rings and large molecular chains of the HEC, which weakened the absorption of ring skeleton.

To confirm the findings from the TEM imaging and FTIR, XPS analysis was employed. Besides carbon (82.3 at\%), oxygen (5.8 at $\%$ ) and nitrogen (8.7 at\%), XPS survey spectrum of the MWNT-triazine contains 3.2 at\% of chlorine (Fig. 4(a)), which arises from chlorine atoms in the triazine rings. In Fig. 4(b), XPS survey spectrum of the MWNT-HEC presents all expected elements with the content of 76.2 at\% (carbon), 19.5 at\% (oxygen) and 4.3 at\% (nitrogen). The absence of chlorine is in agreement with the IR analysis, and further supports the reaction involving chlorine atoms in the triazine rings. As a result of attachment of the HEC moieties, a remarkable increase in oxygen content occurred.
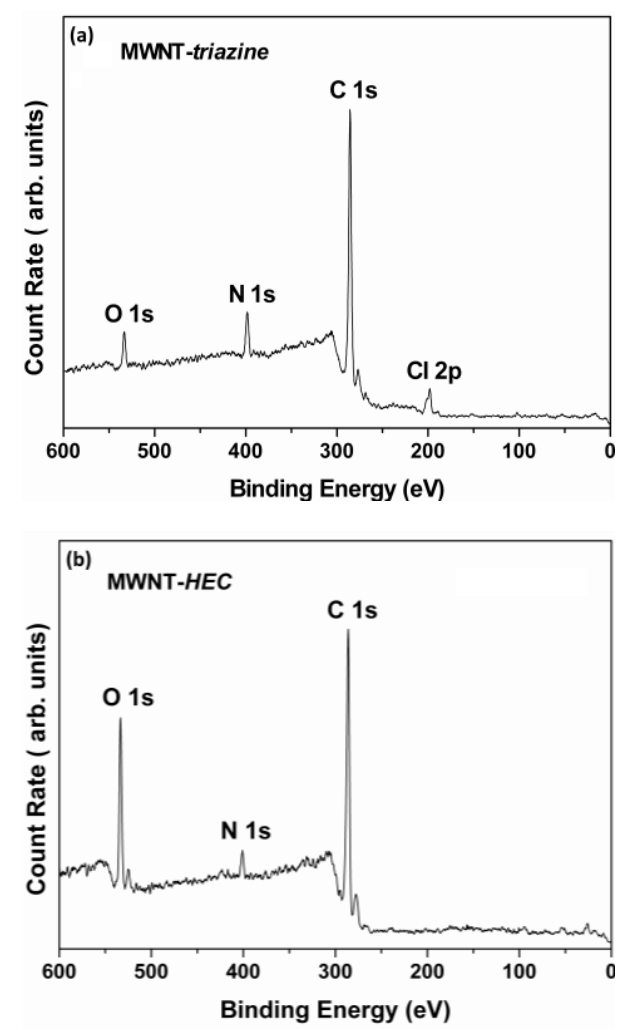

Fig. 4. XPS survey spectrum of (a) MWNT-triazine and (b) MWNT-HEC.

XPS C 1s spectra of the MWNT-triazine and the MWNT-HEC are illustrated in Fig. 5(a, b). The FWHM of the C 1s core level of the MWNT-HEC is larger than that of the MWNT-triazine by $0.54 \mathrm{eV}$. It indicates a more complicated bonding environment in the MWNT-HEC [9, 10]. After functionalization, the characteristic $\mathrm{C} 1 \mathrm{~s}$ peak of the MWNT-triazine at $288.7 \mathrm{eV}$, which arose from the triazine carbon bonded to chloride, was superseded by a new signal with binding energy higher than $289.1 \mathrm{eV}$ (Fig. 5(b)). Once the MWNT-triazine reacted with the HEC, chloride in $\mathrm{N}=C-C l(\mathrm{~N})$ would be replaced by oxygen. Hence a new bond structure of $\mathrm{N}=C-O(\mathrm{~N})$ formed. While oxygen has a better electron-withdrawing ability than chloride, it leads to a decrease in out-shell electron density of carbon bound to oxygen. Thus, the shielding effect weakened, the $\mathrm{C} 1 \mathrm{~s}$ binding energy increased. Similarly, C 1s peak at $285.8 \mathrm{eV}$ that represents the $C-\mathrm{N}$ and $C$-O contributions, shifted to a higher binding energy of $286.3 \mathrm{eV}$. It should be related to the bond structures of $C-\mathrm{O}-C$ and $C-\mathrm{OH}$ in the HEC chains [11]. In addition, the slightly shifting of $\mathrm{C} 1 \mathrm{~s}$ peak at $287.6 \mathrm{eV}$ with an increase in area may arise from the bridge carbon $(\mathrm{O}-\mathrm{C}-\mathrm{O}$, $287.69 \mathrm{eV}$ ) in glucopyranose rings.

XPS N 1s spectra of the MWNT-triazine and the MWNT-HEC are illustrated in Fig. 5(c, d). Both show two components and the same one at $400.2 \mathrm{eV}$. After functionalization, the characteristic emission at $399.1 \mathrm{eV}$ from $N=\mathrm{C}$ in triazine rings of the MWNT-triazine shifted to a higher binding energy of $399.4 \mathrm{eV}$ [12]. It may relate to the 
substitution of chlorine atoms in the the triazine rings by oxygen atoms, and formation of a new structure of $N=\mathrm{C}-\mathrm{O}(\mathrm{N})$. These XPS findings further approve the attachment of HEC to the nanotubes, which is due to the reaction between triazine chloride atoms in the MWNT-triazine and hydroxyl groups in the HEC.
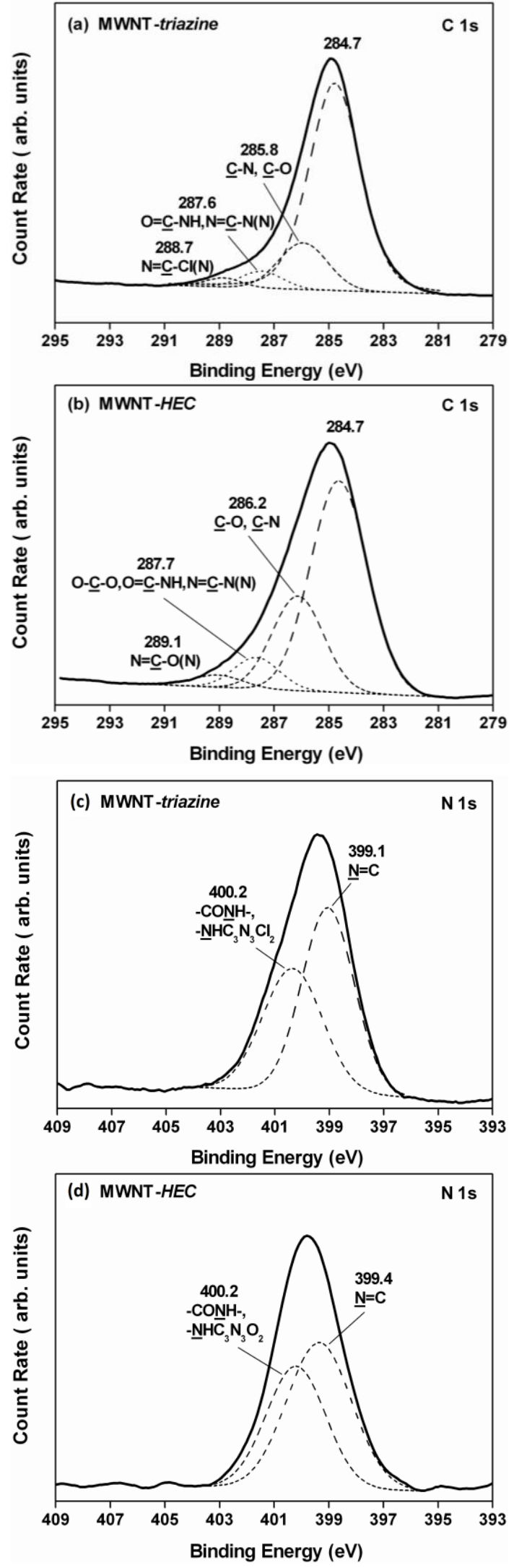

Fig. 5. XPS C 1s spectra of (a) MWNT-triazine and (b) MWNT-HEC, XPS $\mathrm{N}$ 1s spectra of (c) MWNT-triazine and (d) MWNT-HEC.
By thermogravimetric analysis, the MWNT-HEC shows a main and gradual thermal degradation step in the temperature range of $270-700{ }^{\circ} \mathrm{C}$. At $700{ }^{\circ} \mathrm{C}$, weights of the MWNT-triazine and MWNT-HEC are $75.2 \mathrm{wt} \%$ and 46.8 wt $\%$, respectively. Residuary weight of the $\mathrm{HEC}$ at $700^{\circ} \mathrm{C}$ is $11.5 \mathrm{wt} \%$, which arises from charring residuals of the cellulose. Based on the TG data, weight content of the attached hydroxyethyl cellulose in the MWNT-HEC was estimated to be ca. $32.1 \mathrm{wt} \%$.

With aid of the attached HEC moieties, the MWNT-HEC is readily soluble in NMP, DMF, DMAc and DMSO, which makes it possible to mix the MWNT-HEC together with certain cellulose matrices in homogeneous systems in next application step.

\section{CONCLUSION}

In summary, we have demonstrated an efficient method to prepare the novel hybrid material of the carbon nanotubes and the hydroxyethyl cellulose. Detailed characterizations verified that reaction between chloride atoms in the triazine-functionalized MWNTs and hydroxyl groups in the HEC had contributed to the covalent conjugate of the nanotubes and cellulose chains. The hybrid material consists of carbon $(76.2 \%)$, oxygen $(19.5 \%)$ and nitrogen $(4.3 \%)$. With a nanotube-attached cellulose content of $32.1 \mathrm{wt} \%$, the hybrid material is readily soluble in common polar solvents, which makes it possible to mix the MWNT-HEC together with certain cellulose matrices in homogeneous systems in next application step. Further studies aiming at potential applications in specific sorption \& isolation and delivery systems are in process.

\section{REFERENCES}

[1] R. C. Chadwick, J. B. Grande, M. A. Brook, and A. Adronov, "Functionalization of single-walled carbon nanotubes via the piers-rubinsztajn reaction," Macromolecules, vol. 47, no. 18, pp. 6527-6530, September 2014.

[2] W. H. Liao, H. W. Tien, S. T. Hsiao, S. M. Li, Y. S. Wang, Y. L. Huang, S. Y. Yang, C. C. M. Ma, and Y. F. Wu, "Effects of multiwalled carbon nanotubes functionalization on the morphology and mechanical and thermal properties of carbon fiber/vinyl ester composites," ACS Appl. Mater. Interfaces, vol. 5, no. 9, pp 3975-3982, April 2013.

[3] Y. T. Zhao, M. He, L. Zhao, S. Q. Wang, Y. P. Li, L. Gan, M. M. Li, Li $\mathrm{Xu}, \mathrm{P}$. R. Chang, D. P. Anderson, and Y. Chen, "Epichlorohydrin-cross-linked hydroxyethyl cellulose/soy protein isolate composite films as biocompatible and biodegradable implants for tissue engineering," ACS Applied Materials \& Interfaces, vol. 18, no. 4, pp. 2781-2795, January 2016.

[4] F. Joubert, R. P. Yeo, G. J. Sharples, O. M. Musa, D. R. W. Hodgson, and N. R. Cameron, "Preparation of an antibacterial poly(ionic liquid) graft copolymer of hydroxyethyl cellulose," Biomacromolecules, vol. 16, no. 12, pp. 3970-3979, November 2015.

[5] G. Zhang, S. Jiang, W. Yao, and C. Liu, "Enhancement of natural convection by carbon nanotube films covered microchannel-surface for passive electronic cooling devices," ACS Applied Materials \& Interfaces, October 28, 2016.

[6] J. Kim, J. Lee, S. Kim, and W. Jung, "Highly increased flow-induced power generation on plasmonically carbonized single-walled carbon nanotube," ACS Applied Materials \& Interfaces, 2016.

[7] S. Cong, Y. Cao, X. Fang, Y. Wang, Q. Liu, H. Gui, C. Shen, X. Cao, E. S. Kim, and C. Zhou, "Carbon nanotube macroelectronics for active matrix," Polymer-Dispersed Liquid Crystal Displays, ACS Nano, October 20, 2016. 
[8] V. N. Khabashesku, J. L. Zimmerman, and J. L. Margrave, "Powder synthesis and characterization of amorphous carbon nitride," Chemistry of Materials, vol. 12, pp. 3264-3270, October 2000.

[9] S. E. Baker, W. Cai, T. L. Lasseter, K. P. Weidkamp, and R. J. Hamers, "Covalently bonded adducts of deoxyribonucleic acid (DNA) oligonucleotides with single-wall carbon nanotubes: synthesis and hybridization," Nano Letters, vol. 2, pp. 1414-1415, October 2002.

[10] S. Wada, Y. Murata, A. T. Tokunaga, and J. Watanabe, "Experimental study of amorphous silicate formation," Astronomy \& Astrophysics, vol. 406, pp. 783-788, May 2003.

[11] C. D. Wagner, A. V. Naumkin, A. Kraut-Vass, J. W. Allison, C. J. Powell, Jr., and J. R. Rumble, "NIST X-ray photoelectron spectroscopy database, version 3.5," National Institute of Standards and Technology, 2007.

[12] M. Salmain, N. Fischer-Durand, C. Roche, and C. M. Pradier, "Immobilization of atrazine on gold, a first step towards the elaboration of an indirect immunosensor: Characterization by XPS and PM-IRRAS," Surface Interface Analysis, vol. 38, pp. 1276-1284, June 2006

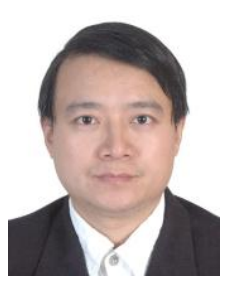

Gang Ke was born in Wuhan city in 1973, China. He received the BS degree in Chemistry from Jianghan University in China in 1994, the master's degree in polymer chemistry and physics chemistry from Hubei Chemistry Research Institute in China in 2003, and the Ph.D. degree in material chemistry and Physics from the Huazhong University of Science and Technology in China in 2007.

He works for State Key Laboratory of Seismic
Reduction/Control and Structural Safety at Guangzhou University in China since 2007. In 2009 he was appointed as a Associate Professor in chemistry at the at Guangzhou University, China. A published paper "Covalent Functionalization of Multiwalled Carbon Nanotubes with a Low Molecular Weight Chitosan, Biomacromolecules, vol. 8, no. 2, pp. 322-326, January 2007," ranked the most accessed 20 papers of annual publication. Therefore he received a congratulatory letter from the American Chemical Society. His research interests are in the areas of preparation and application of nano materials and polymer composite materials.

Dr. Ke is a member of the American Chemical Society (ACS), member of the Asia-Pacific Chemical, Biological \& Environmental Engineering Society (APCBEES), and member of the Chinese Materials Research Society (CMRS). He is also a member of Technical Committee of ICCCP 2017. For scientific achievements in field of nanodiamond and related materials, he was awarded a first prize for progress in science and technology by the Ministry of Education of China in 2014 